\title{
Influência do período de centrifugação na curva de retenção de água em solos de Cerrado(1)
}

\author{
Euzebio Medrado da Silva(2) e Juscelino Antonio de Azevedo(2)
}

\begin{abstract}
Resumo - O período de centrifugação, necessário ao equilíbrio da umidade no solo, é fator determinante da precisão da curva de retenção de umidade. O objetivo deste trabalho foi avaliar o efeito do período de centrifugação na curva de retenção de umidade em cinco tipos de solo da região do Cerrado. As curvas de retenção foram ajustadas por meio de regressão não-linear, e a soma dos erros residuais do ajuste foi utilizada para avaliar as diferenças estatísticas entre elas, pelo teste da razão de verossimilhança. As curvas de retenção de umidade foram agrupadas em famílias de curvas, para cada tipo de solo, para facilitar a visualização das diferenças. Os resultados mostraram claramente que o período de centrifugação afeta a curva de retenção, promovendo, assim, nítida rotação nas curvas em torno do ponto de saturação. Utilizando-se a técnica da regressão inversa, foi possível estabelecer o período de centrifugação necessário ao equilíbrio da umidade, de cada tipo de solo, correspondente ao nível de significância de 5\%, no intervalo de confiança de $90 \%$. Para os solos estudados, o período de centrifugação necessário à extração da água, em cada rotação aplicada, pelo método tradicional da centrífuga, deve ser superior a 80 minutos.
\end{abstract}

Termos para indexação: disponibilidade hídrica, potencial matricial, análise de regressão.

\section{Influence of the centrifugation time in the soil-water retention curve in Cerrado soils}

\begin{abstract}
The centrifugation time, necessary to the equilibrium of soil moisture, is a determinant factor for the precision of the soil-water retention curve. The objective of this work was to evaluate the effect of the centrifugation time on the soil-water retention curve of five soil-types from the Cerrado region. The retention curves were adjusted using non-linear regression, with the sum of minimum square errors being used to evaluate the statistical differences among them. For each soil type, the obtained retention curves were presented as a family of curves to facilitate the visualization of differences among them. The results showed clearly that the time of centrifugation affects the retention curve, imposing a visible rotation on the curves, centered at the saturation point. Using the technique of the inverse regression, it was possible to calculate the necessary time of centrifugation for each soil type, based on the $5 \%$ significance level and $90 \%$ confidence interval. For the studied soils, the time of centrifugation necessary for extracting water from the soil sample up to equilibrium, at each applied rotation, using the traditional method of soil-centrifugation for determining soil-water retention curve, has to be over 80 minutes.
\end{abstract}

Index terms: water availability, matric potential, regression analysis.

\section{Introdução}

A técnica da centrifugação de amostras de solo para determinar a relação entre o conteúdo de umidade e a tensão com que ela está retida no solo é bastante antiga (Briggs \& McLane, 1910) e é objeto de vários estudos (Odén, 1976; Freitas Júnior \& Silva, 1984; Medeiros, 1987). Estes autores mostraram

\footnotetext{
(1) Aceito para publicação em 23 de maio de 2002.

(2) Embrapa-Centro de Pesquisa Agropecuária dos Cerrados, Caixa Postal 08223, CEP 73301-970 Planaltina, DF. E-mail: euzebio@cpac.embrapa.br, juscelin@cpac.embrapa.br
}

as limitações e potencialidades da utilização do levantamento da curva de retenção da umidade do solo em laboratório. Entre as vantagens reconhecidas desse método, destaca-se a rapidez na obtenção do equilíbrio da umidade no solo submetido a centrifugação, normalmente menos de seis horas (Odén, 1976; Freitas Júnior \& Silva, 1984). O método da câmara de pressão de Richards (Richards \& Fireman, 1943) envolve períodos de, no mínimo, 24 horas para o equilíbrio. Por outro lado, destacam-se desvantagens, tais como possíveis erros causados pela compactação das amostras de solo, durante o processo de centrifugação (Freitas Júnior \& Silva, 
1984). Cabe destacar, ainda, que Malcom \& Andrée (1991) reconheceram a importância desse método, ao incluí-lo entre os procedimentos de determinação da curva de retenção de umidade do solo.

Depreende-se, dos trabalhos acima referidos, que o período de centrifugação necessário ao equilíbrio da umidade no solo, em dada rotação, é fator determinante da precisão da curva de retenção. Baseado nisso, Odén (1976) recomendou períodos de centrifugação variando de 5 a 60 minutos, dependendo da faixa de tensão desejada, ressalvando, contudo, que esse período depende da composição granulométrica do solo. Freitas Júnior \& Silva (1984) analisaram o efeito do período de centrifugação em amostras de um Latossolo Vermelho do Cerrado, e sugeriram que três horas são necessárias para determinar a curva de retenção da umidade no solo em uma única operação, utilizando a técnica do fatiamento de amostras de solo. Esses estudos evidenciam que a questão do período de centrifugação necessário para o equilíbrio ainda precisa ser investigada, considerando principalmente a variação dessa resposta de acordo com o tipo de solo.

O objetivo do trabalho foi estudar a influência do período de centrifugação na curva de retenção de umidade de vários solos de cerrado.

\section{Material e Métodos}

O solo saturado, quando submetido a centrifugação, gera uma tensão de umidade decrescente ao longo do eixo de rotação da centrífuga. De maneira geral, a distribuição da tensão ao longo do eixo pode ser prevista pela seguinte equação (Freitas Júnior \& Silva, 1984):

$\mathrm{dh}_{\mathrm{r}}=-\omega^{2} g^{-1} \mathrm{rdr}$,

onde $\mathrm{dh}_{\mathrm{r}}$ é o diferencial da tensão da umidade na amostra de solo $(\mathrm{cm})$ causado pela centrifugação; $\omega$ é a velocidade angular $\left(\mathrm{rad} \mathrm{s}^{-1}\right) ; g$ é a aceleração da gravidade $\left(981 \mathrm{~cm} \mathrm{~s}^{-2}\right)$; r é a distância do eixo da centrífuga até determinada seção transversal da amostra $(\mathrm{cm})$; dr é o diferencial de r. A integração da equação 1 , no intervalo de r até a superfície externa da amostra - a qual é mantida sempre saturada durante o processo de centrifugação -, resulta na função que descreve a variação da tensão da umidade ao longo da amostra de solo após o equilíbrio, ou seja:

$\mathrm{h}_{\mathrm{r}}=\frac{1}{2} \omega^{2} g^{-1}\left(\mathrm{r}_{\mathrm{e}}^{2}-\mathrm{r}^{2}\right)$, onde $\mathrm{h}_{\mathrm{r}}$ é a tensão da umidade na amostra de solo $(\mathrm{cm})$ na superfície $r$, causada pela centrifugação; $r_{\mathrm{e}}$ é o raio externo (cm) da amostra de solo na centrífuga.

A tensão média $\overline{\mathrm{h}}$, estabelecida na amostra de solo, no intervalo de $\mathrm{r}_{\mathrm{i}}$ (raio interno) a $\mathrm{r}_{\mathrm{e}}$, é determinada pela seguinte equação (Freitas Júnior \& Silva, 1984):

$$
\overline{\mathrm{h}}=\frac{1}{6} \omega^{2} \mathrm{~g}^{-1} \mathrm{~L}\left(3 \mathrm{r}_{\mathrm{e}}-\mathrm{L}\right)
$$

onde L é o comprimento da amostra ao longo do eixo da centrífuga $(\mathrm{cm})$, ou seja, a diferença $\left(\mathrm{r}_{\mathrm{e}}-\mathrm{r}_{\mathrm{i}}\right)$. No caso da centrífuga modelo $\mathrm{H}-1400 \mathrm{pF}$ (Kokusan Corporation, 1999), utilizada no presente estudo, $r_{\mathrm{e}}=8,3 \mathrm{~cm} \mathrm{e} \mathrm{L}=5 \mathrm{~cm}$.

Considerando a tensão média $\overline{\mathrm{h}}(\mathrm{kPa})$ e a velocidade angular $\omega(\mathrm{rpm})$, a equação 3 pode ser reduzida a:

$\omega=\mathrm{K} \sqrt{\overline{\mathrm{h}}}$,

onde $\mathrm{K}=234,5192$. Esta constante pode ser calculada pela seguinte equação:

$$
\mathrm{K}=\frac{60}{2 \pi} \sqrt{\frac{6 \times 981 \times 10,1957}{\mathrm{~L}\left(3 \mathrm{r}_{\mathrm{e}}-\mathrm{L}\right)}} .
$$

Foram aplicadas rotações de 600, 800, 1.400, 2.000, 2.400 e $9.200 \mathrm{rpm}$, correspondentes às tensões médias de $6,55,11,64,35,64,72,73,104,73$ e $1.538,92 \mathrm{kPa}$, utilizando quatro amostras (repetições) de cada tipo de solo. Ao final dos períodos de centrifugação de 15, 30, 60, 120, 180, 240,300 e 360 minutos, determinou-se, por meio de pesagens sucessivas, o conteúdo de umidade remanescente nas amostras de solo. A média do conteúdo de umidade de quatro repetições, em cada rotação, foi utilizada no levantamento da curva de retenção de umidade do solo, em razão do período de centrifugação utilizado, gerando uma família com oito curvas de retenção em cada tipo de solo estudado.

O modelo de Genutchen (1980), indicado como um dos mais adequados na representação do fenômeno da retenção da umidade no solo (Genutchen \& Nielsen, 1985; Kool et al., 1987; Silva, 1990), foi representado pela seguinte equação:

$$
\frac{\theta-\theta_{\mathrm{r}}}{\theta_{\mathrm{s}}-\theta_{\mathrm{r}}}=\left[\frac{1}{1+(\alpha \mathrm{h})^{\mathrm{n}}}\right]^{(1-1 / \mathrm{n})}
$$

onde $\theta$ é o conteúdo de umidade no solo $\left(\mathrm{cm}^{3} \mathrm{~cm}^{-3}\right) ; \theta_{\mathrm{r}}$ é o conteúdo residual de umidade no solo $\left(\mathrm{cm}^{3} \mathrm{~cm}^{-3}\right) ; \theta_{\mathrm{s}}$ é o conteúdo saturado de umidade no solo $\left(\mathrm{cm}^{3} \mathrm{~cm}^{-3}\right)$; h é a tensão da umidade no solo gerado pela centrifugação $(\mathrm{kPa})$; n é o parâmetro empírico de ajuste (adimensional); 
$\alpha$ é o parâmetro empírico de ajuste $\left(\mathrm{kPa}^{-1}\right)$. No presente trabalho, o modelo de Genutchen (1980) foi reduzido a dois parâmetros de ajuste, adotando-se $\theta_{\mathrm{s}}$ igual à porosidade total (Rogowski, 1971) e $\theta_{\mathrm{r}}$ equivalente ao conteúdo de umidade na maior tensão do estudo (Genutchen, 1980; Assouline et al.,1998), usando-se os demais cinco pontos de tensão para realização do ajuste. O ajuste dos parâmetros $(n, \alpha)$ foi feito utilizando procedimentos de regressão não-linear já consagrados (Microsoft Corporation, 1994).

Foram utilizadas amostras dos três principais solos do Cerrado (Adámoli et al., 1985): Latossolo Vermelho-Amarelo (LVA), Latossolo Vermelho (LV) e Neossolo Quartzarênico (RQ), sendo três tipos do LVA, classe de solo predominante no Cerrado, e um tipo de cada uma das demais classes. As características texturais dos solos encontram-se na Tabela 1. De cada tipo, foram retiradas 24 amostras não-deformadas da superfície do solo, em cilindros de $5 \mathrm{~cm}$ de altura e volume de $100 \mathrm{~cm}^{3}$. A média de densidade do solo, de cada conjunto de 24 amostras secadas a $105^{\circ} \mathrm{C}$, foi utilizada no cálculo da porosidade total, assumindo a densidade das partículas igual a $2,65 \mathrm{~g} \mathrm{~cm}^{-3}$. Esse valor de porosidade foi utilizado como referência paramétrica no modelo de ajuste em cada tipo de solo estudado.

A análise estatística empregada teve por objetivo principal fornecer a métrica probabilística adequada para avaliação das diferenças encontradas entre as curvas de retenção de um mesmo tipo de solo resultante da aplicação dos diferentes períodos de centrifugação. Neste caso, adotouse o teste da razão de verossimilhança (Souza, 1998), que consiste em comparar a diferença entre a soma de quadrados residuais de dois modelos ajustados, utilizando o teste $\mathrm{F}$ para definir o nível de significância da diferença observada. A comparação foi realizada tomando-se o modelo da curva de retenção, ajustada no período de centrifugação de 360 minutos, como sendo a curva estabilizada, a qual serviu de base para determinação das diferenças com as demais curvas de retenção. $\mathrm{O}$ teste da razão de

Tabela 1. Distribuição do tamanho de partículas dos diferentes tipos de $\operatorname{solos}^{(1)}$.

\begin{tabular}{|c|c|c|c|c|c|}
\hline \multirow[t]{2}{*}{ Partículas } & \multicolumn{3}{|c|}{ L V A } & \multirow[t]{2}{*}{ R Q } & \multirow[t]{2}{*}{$\mathrm{L} \mathrm{V}$} \\
\hline & $\begin{array}{c}\text { Muito } \\
\text { argiloso }\end{array}$ & $\begin{array}{l}\text { Argilo- } \\
\text { arenoso }\end{array}$ & $\begin{array}{l}\text { Franco- } \\
\text { arenoso }\end{array}$ & & \\
\hline & --------- & - & (\%) & - & 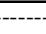 \\
\hline Argila & 65 & 45 & 19 & 7 & 57 \\
\hline Silte & 14 & 7 & 0 & 0 & 3 \\
\hline Areia fina & 5 & 11 & 43 & 20 & 9 \\
\hline Areia grossa & 16 & 37 & 38 & 73 & 31 \\
\hline
\end{tabular}

(1)LVA: Latossolo Vermelho-Amarelo; RQ: Neossolo Quartzarênico; LV: Latossolo Vermelho. verossimilhança pode ser transformado em teste $\mathrm{F}$ (Souza, 1998), o qual, neste procedimento, foi representado pela seguinte equação:

$$
\mathrm{F}=\frac{\left[\mathrm{SSE}_{\mathrm{comb}}-\left(\mathrm{SSE}_{\mathrm{T}}+\mathrm{SSE}_{360}\right)\right] / 2}{\left(\mathrm{SSE}_{\mathrm{T}}+\mathrm{SSE}_{360}\right) / 6},
$$

onde $\mathrm{F}$ é o valor da distribuição $\mathrm{F}$ correspondente à razão da diferença entre a soma dos quadrados residuais da curva de retenção, em um dado período de centrifugação T, em relação ao período de centrifugação de 360 minutos; $\mathrm{SSE}_{\mathrm{T}}$ é a soma dos quadrados residuais da curva de retenção, em um dado período de centrifugação (exceto 360 minutos); $\mathrm{SSE}_{360}$ é a soma dos quadrados residuais da curva de retenção no período de centrifugação de 360 minutos; $\mathrm{SSE}_{\text {comb é }}$ a soma dos quadrados residuais da curva de retenção, resultante do ajuste com os dados provenientes do período de centrifugação de 360 minutos, combinados com os dados de cada um dos demais períodos de centrifugação. Os divisores 2 e 6 representam os respectivos graus de liberdade do numerador e denominador, utilizados no cálculo da razão entre os quadrados médios residuais de cada par de curvas comparadas. Neste caso, o valor crítico de $\mathrm{F}_{(0,05 ; 2 ; 6)}$, correspondente ao nível de significância de 5\%, é igual a 5,14325, segundo a Microsoft Corporation (1994).

Os valores de $\mathrm{F}$ calculados pela equação 7 podem ser representados de forma contínua, de acordo com o período de centrifugação, ajustando-se os pares de dados (F, T) a um modelo previamente identificado. Empregou-se o modelo linear, ajustando-se o logaritmo neperiano dos valores de $\mathrm{F}$ (ln F) de acordo com os períodos de centrifugação, no intervalo de 15 a 300 minutos; foi possível, então, determinar o período de centrifugação, $\mathrm{T}_{0}$, equivalente ao nível crítico de significância de $5 \%$, correspondente a $\ln \mathrm{F}_{0}=1,6377$. Adotando-se o procedimento da regressão inversa (Draper \& Smith, 1981), foi possível determinar o intervalo de confiança associado a $\mathrm{T}_{0}$, depois de ser conhecida sua variância. Para isso, foi necessário considerar a seguinte equação:

$\mathrm{T}_{0}=\frac{\left(\ln \mathrm{F}_{0}-\mathrm{a}\right)}{\mathrm{b}}$,

onde a e b são os parâmetros da equação linear.

Utilizando-se os procedimentos tradicionais de cálculo de variância (Draper \& Smith, 1981), pode-se derivar a seguinte equação:

$\operatorname{var}\left(\mathrm{T}_{0}\right)=\frac{\operatorname{var}(\mathrm{a})}{\mathrm{b}^{2}}-\frac{2\left(\mathrm{a}-\ln \mathrm{F}_{0}\right) \operatorname{cov}(\mathrm{a}, \mathrm{b})}{\mathrm{b}^{3}}+\frac{\left(\mathrm{a}-\ln \mathrm{F}_{0}\right)^{2} \operatorname{var}(\mathrm{b})}{\mathrm{b}^{4}}$,

onde os símbolos var e cov representam, respectivamente, variância e covariância dos termos entre parênteses. 
Desta forma, pode-se indicar, com $90 \%$ de confiança, que os limites superior e inferior, representados por $T_{c} e$ expressos em minutos, encontram-se no intervalo definido pela seguinte equação:

$\mathrm{T}_{\mathrm{c}}=\mathrm{T}_{0} \pm 2,015 \sqrt{\operatorname{var}\left(\mathrm{T}_{0}\right)}$,

onde a constante 2,015, segundo Abramowitz \& Stegun (1972), representa o valor da distribuição t com 5 graus de liberdade e $10 \%$ de probabilidade de erro total. Neste procedimento, quanto maior for o coeficiente de correlação da regressão linear, menor será a variância de $\mathrm{T}_{0}, \mathrm{e}$, conseqüentemente, menor será o intervalo de confiança calculado.

\section{Resultados e Discussão}

As curvas de retenção que relacionam o conteúdo de umidade e a tensão com que a umidade está retida no solo, dependendo do período de centrifugação, foram ajustadas ao modelo de Genutchen (1980) e agrupadas em famílias, em cada tipo de solo analisado. Os parâmetros $\left(\mathrm{q}_{\mathrm{s}}, \mathrm{q}_{\mathrm{r}}, \mathrm{n}\right.$, a) das curvas de retenção ajustadas estão na Tabela 2. É importante relembrar que apenas os parâmetros n e a foram ajustados pelo procedimento de regressão não-linear. Os demais parâmetros foram fixados, e portanto, excluídos do procedimento de ajuste.

Tabela 2. Parâmetros de ajuste das curvas de retenção de umidade, segundo o modelo de Genutchen (1980), de diferentes tipos de solo, em razão do período de centrifugação, adotando-se a porosidade total como $\theta_{\mathrm{s}}$ e o conteúdo de umidade na tensão de $1.532,92 \mathrm{kPa}$ como $\theta_{\mathrm{r}}$, com os valores de $\mathrm{n}$ e $\alpha$ determinados pelo procedimento de regressão não-linear.

\begin{tabular}{|c|c|c|c|c|c|c|}
\hline \multirow{2}{*}{$\begin{array}{c}\text { Período de } \\
\text { Centrifugação } \\
\text { (minutos) }\end{array}$} & \multirow[t]{2}{*}{ Parâmetros } & \multicolumn{3}{|c|}{ Latossolo Vermelho-Amarelo } & \multirow{2}{*}{$\begin{array}{c}\text { Neossolo } \\
\text { Quartzarênico }\end{array}$} & \multirow{2}{*}{$\begin{array}{c}\text { Latossolo } \\
\text { Vermelho } \\
\text { argiloso }\end{array}$} \\
\hline & & Muito argiloso & Argilo-arenoso & Franco-arenoso & & \\
\hline \multirow[t]{4}{*}{15} & $\theta_{\mathrm{s}}$ & 0,6419 & 0,6181 & 0,5302 & 0,4728 & 0,6321 \\
\hline & $\theta_{\mathrm{r}}$ & 0,2625 & 0,2014 & 0,1373 & 0,0907 & 0,2225 \\
\hline & $\mathrm{n}$ & 1,8716 & 1,3968 & 1,5245 & 1,6108 & 1,3701 \\
\hline & $\alpha$ & 0,5389 & 1,8074 & 1,0535 & 0,7306 & 3,8158 \\
\hline \multirow[t]{4}{*}{30} & $\theta_{\mathrm{s}}$ & 0,6419 & 0,6181 & 0,5302 & 0,4728 & 0,6321 \\
\hline & $\theta_{\mathrm{r}}$ & 0,2549 & 0,1414 & 0,1285 & 0,0852 & 0,2141 \\
\hline & $\mathrm{n}$ & 1,7999 & 1,3823 & 1,4980 & 1,5591 & 1,3541 \\
\hline & $\alpha$ & 0,6219 & 2,0678 & 1,2239 & 0,8095 & 4,3477 \\
\hline \multirow[t]{4}{*}{60} & $\theta_{\mathrm{s}}$ & 0,6419 & 0,6181 & 0,5302 & 0,4728 & 0,6321 \\
\hline & $\theta_{\mathrm{r}}$ & 0,2478 & 0,1845 & 0,1225 & 0,0820 & 0,2047 \\
\hline & $\mathrm{n}$ & 1,7355 & 1,3807 & 1,4987 & 1,6034 & 1,3529 \\
\hline & $\alpha$ & 0,7299 & 2,1618 & 1,2312 & 0,8163 & 4,0059 \\
\hline \multirow[t]{4}{*}{120} & $\theta_{\mathrm{s}}$ & 0,6419 & 0,6181 & 0,5302 & 0,4728 & 0,6321 \\
\hline & $\theta_{\mathrm{r}}$ & 0,2426 & 0,1767 & 0,1162 & 0,0780 & 0,1975 \\
\hline & $n$ & 1,7422 & 1,3794 & 1,5050 & 1,6161 & 1,3435 \\
\hline & $\alpha$ & 0,7015 & 2,1593 & 1,2292 & 0,7973 & 4,4055 \\
\hline \multirow[t]{4}{*}{180} & $\theta_{\mathrm{s}}$ & 0,6419 & 0,6181 & 0,5302 & 0,4728 & 0,6321 \\
\hline & $\theta_{\mathrm{r}}$ & 0,2394 & 0,1724 & 0,1139 & 0,0728 & 0,1957 \\
\hline & $\mathrm{n}$ & 1,7178 & 1,3732 & 1,4993 & 1,6182 & 1,3465 \\
\hline & $\alpha$ & 0,7449 & 2,2789 & 1,3056 & 0,8160 & 4,7083 \\
\hline \multirow[t]{4}{*}{240} & $\theta_{\mathrm{s}}$ & 0,6419 & 0,6181 & 0,5302 & 0,4728 & 0,6321 \\
\hline & $\theta_{\mathrm{r}}$ & 0,2394 & 0,1713 & 0,1107 & 0,0707 & 0,1939 \\
\hline & $n$ & 1,7174 & 1,3727 & 1,4933 & 1,5984 & 1,3404 \\
\hline & $\alpha$ & 0,7696 & 2,2998 & 1,3280 & 0,8643 & 5,1882 \\
\hline \multirow[t]{4}{*}{300} & $\theta_{\mathrm{s}}$ & 0,6419 & 0,6181 & 0,5302 & 0,4728 & 0,6321 \\
\hline & $\theta_{\mathrm{r}}$ & 0,2379 & 0,1686 & 0,1082 & 0,0697 & 0,1911 \\
\hline & $\mathrm{n}$ & 1,7198 & 1,3774 & 1,4936 & 1,6160 & 1,3330 \\
\hline & $\alpha$ & 0,7546 & 2,2181 & 1,3152 & 0,8207 & 5,4706 \\
\hline \multirow[t]{4}{*}{360} & $\theta_{\mathrm{s}}$ & 0,6419 & 0,6181 & 0,5302 & 0,4728 & 0,6321 \\
\hline & $\theta_{\mathrm{r}}$ & 0,2372 & 0,1673 & 0,1064 & 0,0696 & 0,1891 \\
\hline & $\mathrm{n}$ & 1,7189 & 1,3823 & 1,4932 & 1,6272 & 1,3248 \\
\hline & $\alpha$ & 0,7559 & 2,1354 & 1,3051 & 0,7947 & 5,9946 \\
\hline
\end{tabular}


Na Figura 1, estão as famílias de curvas do LVA, correspondentes às texturas muito argilosa, argilo-arenosa e franco-arenosa. Em cada família de curva, o ponto de origem foi o mesmo, ou seja, $\mathrm{q}_{\mathrm{s}}$, equivalente à porosidade total do respectivo solo. É importante destacar que essas famílias de curvas apresentaram formatos semelhantes, apenas deslocadas verticalmente em relação ao ponto de saturação de umidade da amostra.

As curvas da Figura 1 apresentam claramente as duas inflexões características do modelo, ou seja, uma logo após a saturação, correspondente ao valor provável de entrada de ar na matriz porosa do solo, e a outra, correspondente à assíntota definida pela umidade residual. A semelhança entre as famílias de curvas confirma que os solos provêm de meios porosos similares. Na apresentação gráfica, estendeuse deliberadamente a representação da tensão de umidade no solo até o valor de $0,01 \mathrm{kPa}$, com o objetivo de enfatizar a origem única de cada família de curvas e destacar a tendência divergente das curvas de retenção com o aumento da tensão, de acordo com o período de centrifugação. Assim, fica evidente a divergência das curvas de retenção em relação à curva considerada como estabilizada no período de centrifugação de 360 minutos, na medida em que o período de centrifugação decresce. Esta constatação contraria a idéia de Freitas Júnior \& Silva (1984) de utilizar a condição aparente de paralelismo entre as curvas e estabelecer fatores de correção para determinar a curva de retenção verdadeira, uma vez co-
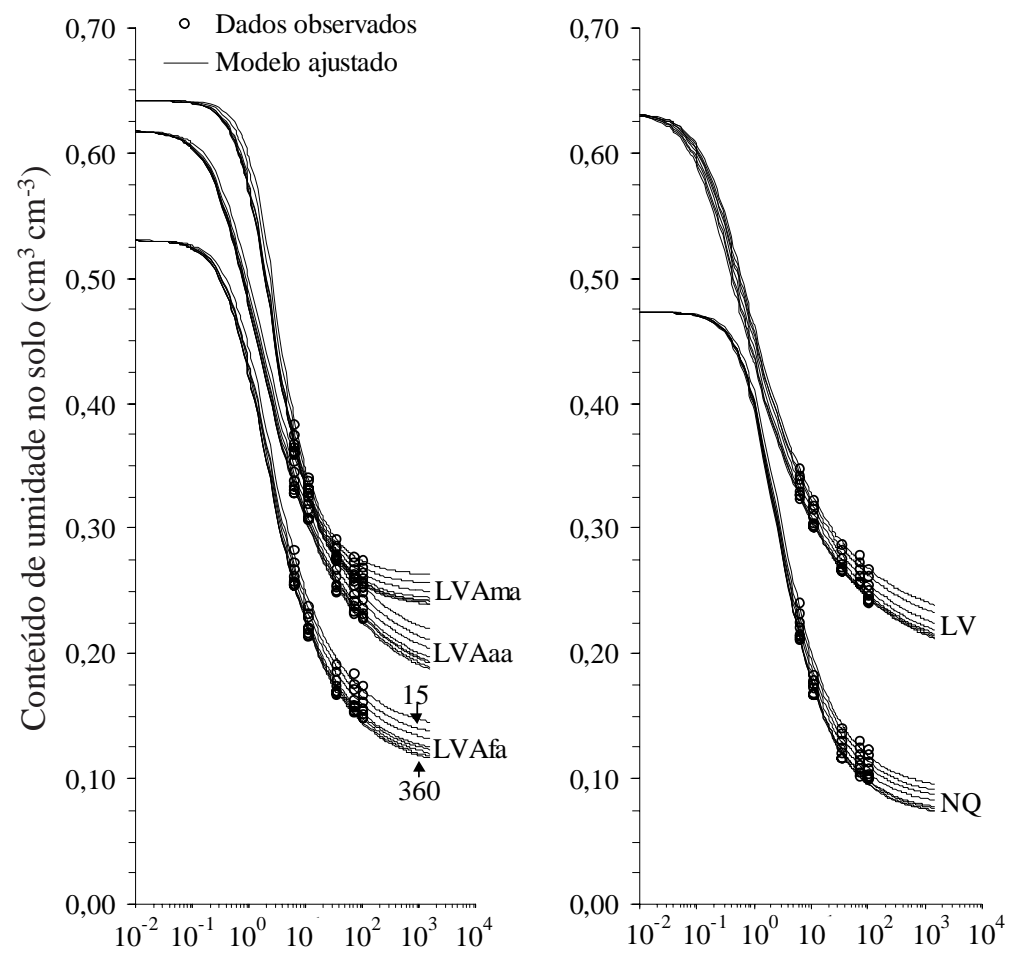

Tensão de umidade no solo $(\mathrm{kPa})$

Figura 1. Famílias de curvas de retenção de umidade, ajustadas a três tipos de Latossolo Vermelho-Amarelo (muito argiloso: LVAma; argilo-arenoso: LVAaa; franco-arenoso: LVAfa), ao Neossolo Quartzarênico (RQ) e ao Latossolo Vermelho argiloso (LV) do Cerrado, utilizando-se oito períodos de centrifugação $(15,30$, $60,120,180,240,300$ e $360 \mathrm{~min}$ ) de cada amostra. 
nhecida uma curva de retenção determinada com período de centrifugação inferior ao adequado.

Na Figura 1, constam, ainda, as famílias de curvas do LV, textura argilosa, e do RQ. Neste caso, é visível a diferença nos formatos das curvas de retenção. A família representativa do RQ é mais parecida com as curvas de retenção do LVA, pois apresenta uma divergência mais acentuada em relação à curva estabilizada, apenas nas tensões maiores. No caso do $\mathrm{LV}$, a divergência entre as curvas se apresenta desde as tensões mais baixas, acentuando-se com o aumento da tensão. A diferença entre as famílias de curvas de retenção dos dois solos reflete a natureza mineralógica e estrutural diferente destes meios porosos.

Analisando-se os parâmetros de ajuste n e a, e de umidade residual, $\mathrm{q}_{\mathrm{r}}$, em todos os casos estudados (Tabela 2), verifica-se claramente que o aumento no período de centrifugação reduziu de forma sistemática o parâmetro $\mathrm{q}_{\mathrm{r}}$ para valores próximos ao $\mathrm{q}_{\mathrm{r}}$ correspondente à curva de retenção determinada com o período de centrifugação de 360 minutos. Verificouse, também, que os parâmetros n e a em geral oscilaram em torno de um valor constante, independentemente do período de centrifugação, exceto quanto aos valores de a do LV argiloso, que apresentou tendência crescente com o aumento do período de centrifugação. Esses resultados indicam que o erro no período de centrifugação não afetou tanto a forma das curvas ajustadas, mas afetou o valor da umidade residual de cada uma delas, produzindo uma espécie de rotação da curva em torno de seu ponto de saturação. Este fato é fisicamente compatível com o procedimento empregado na determinação da curva de retenção, haja vista que este ponto da curva é independente do período de centrifugação. Assim, o erro induzido ao se utilizar um período de centrifugação menor do que o necessário para o equilíbrio terá efeito na estimativa da disponibilidade de água no solo, calculada a partir da curva de retenção ajustada, por causa do erro introduzido na determinação da umidade residual.

Os resultados obtidos, decorrentes da avaliação do período de centrifugação, considerando os diferentes tipos de solos, estão apresentados na Tabela 3. Em cada período de centrifugação, foi calculado um valor $\mathrm{F}$ e seu correspondente nível de significância NS, e comparou-se a soma de quadrados residuais da curva de retenção ajustada com a soma de quadrados do resíduo da curva obtida no período de centrifugação de 360 minutos. Considerando o nível crítico de significância de 5\%, os resultados de F e NS indicam que o período de centrifugação adequado, nos três tipos de LVA, está entre 60 e 120 minutos, e no RQ e LV argiloso, encontra-se entre 120 e 180 minutos. Este resultado concorda com a recomendação de Freitas Júnior \& Silva (1984), que selecionaram o tempo de equilíbrio de três horas para um LV argiloso do Cerrado.

O nível de significância de 5\% representa o limite de erro na decisão de se descartar como verdadeira a hipótese de igualdade entre os modelos. Isto significa que os modelos devem ser considerados diferentes quando o nível de significância calculado for igual ou menor do que $5 \%$. Neste tipo de teste, quanto maior for o valor de $\mathrm{F}$, maior é a diferença entre os

Tabela 3. Valores de F e os correspondentes níveis de significância (NS, \%), resultantes da razão de verossimilhança entre a soma de quadrados dos resíduos do ajuste da curva de retenção de umidade em cada período de centrifugação, e a respectiva soma de quadrados correspondente ao período de centrifugação de 360 min, considerando-se dois e seis graus de liberdade para numerador e denominador, respectivamente.

\begin{tabular}{|c|c|c|c|c|c|c|c|c|c|c|}
\hline \multirow{3}{*}{$\begin{array}{c}\text { Período de } \\
\text { centrifugação } \\
\text { (minutos) }\end{array}$} & \multicolumn{6}{|c|}{ Latossolo Vermelho-Amarelo } & \multirow{2}{*}{\multicolumn{2}{|c|}{$\begin{array}{c}\text { Neossolo } \\
\text { Quartzarênico }\end{array}$}} & \multirow{2}{*}{\multicolumn{2}{|c|}{$\begin{array}{c}\text { Latossolo Vermelho } \\
\text { argiloso }\end{array}$}} \\
\hline & \multicolumn{2}{|c|}{ Muito argiloso } & \multicolumn{2}{|c|}{ Argilo-arenoso } & \multicolumn{2}{|c|}{ Franco-arenoso } & & & & \\
\hline & $\mathrm{F}$ & $\mathrm{NS}^{(1)}$ & $\mathrm{F}$ & NS & $\mathrm{F}$ & NS & $\mathrm{F}$ & NS & $\mathrm{F}$ & NS \\
\hline 15 & 37,096 & 0,042 & 29,893 & 0,076 & 34,063 & 0,053 & 17,126 & 0,331 & 63,879 & 0,009 \\
\hline 30 & 16,731 & 0,351 & 13,661 & 0,584 & 25,078 & 0,122 & 12,578 & 0,714 & 38,066 & 0,039 \\
\hline 60 & 7,112 & 2,611 & 6,286 & 3,372 & 12,135 & 0,779 & 10,713 & 1,047 & 20,175 & 0,217 \\
\hline 120 & 1,439 & 30,860 & 2,151 & 19,751 & 4,178 & 7,299 & 5,132 & 5,020 & 8,840 & 1,627 \\
\hline 180 & 0,495 & 63,269 & 1,095 & 39,305 & 1,725 & 25,589 & 0,586 & 58,562 & 2,079 & 20,608 \\
\hline 240 & 0,229 & 80,162 & 0,783 & 49,885 & 0,693 & 53,622 & 0,613 & 57,229 & 0,400 & 68,680 \\
\hline 300 & 0,030 & 97,091 & 0,090 & 91,498 & 0,108 & 89,949 & 0,051 & 95,093 & 0,124 & 88,526 \\
\hline
\end{tabular}

(1)NS = 100 [(1 - distribuição F (F, 2, 6)]. 
modelos, e menor é o risco de erro ao se rejeitar a hipótese verdadeira de igualdade entre eles. Além disso, convém salientar que, quanto menor for o nível de significância encontrado, mais evidente é a diferença entre os modelos.

Empregando-se a técnica da regressão inversa, recomendada por Draper \& Smith (1981), foi possível estimar o período de centrifugação equivalente ao nível de significância de 5\% e seu respectivo intervalo de variação com um nível de confiança de $90 \%$. Para isso, foi necessário realizar o ajuste linear do logaritmo neperiano de $\mathrm{F}$ de acordo com o período de centrifugação, em cada tipo de solo estudado, para determinar estatisticamente o período necessário ao equilíbrio, correspondente ao NS de 5\% ( $\left.\ln \mathrm{F}_{0}=1,6377\right)$, em cada tipo de solo estudado. Esses resultados estão apresentados na Figura 2, com o nível crítico de significância representado pela linha horizontal tracejada. A interseção dessa linha com cada um dos modelos lineares ajustados determina, na abscissa, o período adequado para o equilíbrio da tensão da umidade no momento da centrifugação, nos solos analisados.

É importante destacar, nesse tipo de análise, que a amplitude do intervalo de confiança depende também do grau de ajuste do modelo linearizado. Na Tabela 4, estão apresentados os resultados completos deste ajuste, os quais indicam que as piores correlações foram obtidas com o LVA argilo-arenoso

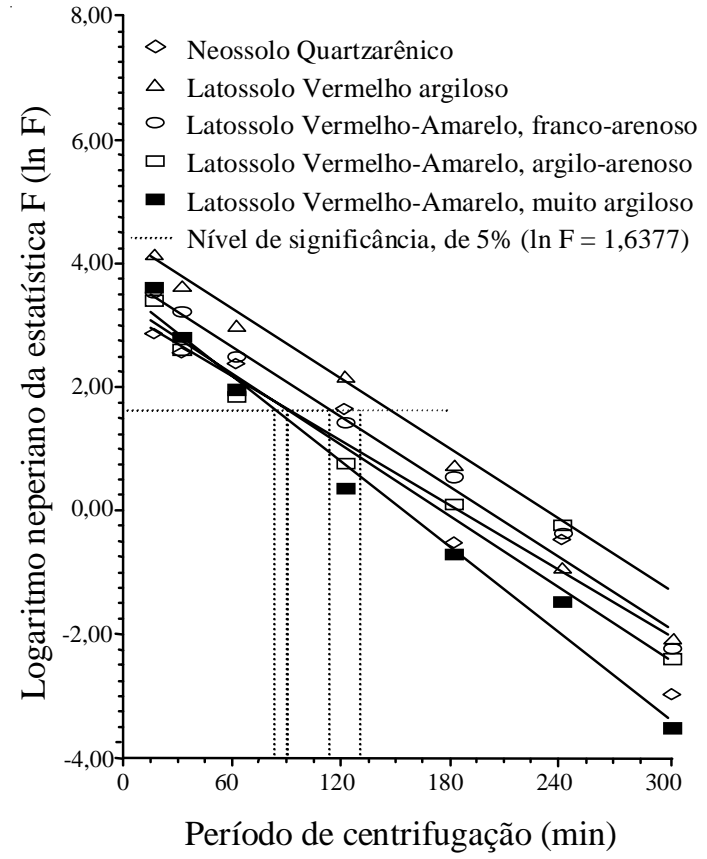

Figura 2. Valores da distribuição estatística F (com dois e seis graus de liberdade no numerador e denominador, respectivamente), em razão do período de centrifugação, tendo como referência o período de 360 minutos, ajustados ao modelo de regressão linear para determinação do período de centrifugação correspondente a $5 \%$ de significância.

Tabela 4. Valores resultantes da regressão linear entre o logaritmo neperiano dos valores de F e o período de centrifugação, no cálculo do tempo de equilíbrio correspondente ao valor crítico de significância de $\mathrm{F}$ de $5 \%\left(\ln \mathrm{F}_{0}=1,637\right)$, em diferentes tipos de solo, considerando dois e seis graus de liberdade para numerador e denominador, respectivamente ${ }^{(1)}$.

\begin{tabular}{|c|c|c|c|c|c|}
\hline \multirow[t]{2}{*}{ Variáveis } & \multicolumn{3}{|c|}{ Latossolo Vermelho-Amarelo } & \multirow[t]{2}{*}{ Neossolo Quartzarênico } & \multirow[t]{2}{*}{ Latossolo Vermelho argiloso } \\
\hline & Muito argiloso & Argilo-arenoso & Franco-arenoso & & \\
\hline $\mathrm{R}^{2}$ da regressão linear & 0,9824 & 0,9514 & 0,9875 & 0,9435 & 0,9935 \\
\hline Interseção (a) & 3,5483 & 3,2241 & 3,7832 & 3,3648 & 4,4475 \\
\hline Inclinação (b) & $-0,0230$ & $-0,0175$ & $-0,0189$ & $-0,0192$ & $-0,0216$ \\
\hline Covariância $(a, b)$ & $-2,574 \mathrm{E}-4$ & $-4,215 \mathrm{E}-4$ & $-1,220 \mathrm{E}-4$ & $-5,986 \mathrm{E}-4$ & $-8,215 \mathrm{E}-5$ \\
\hline Variância de (a) & 0,054234 & 0,088810 & 0,025699 & 0,126128 & 0,017311 \\
\hline Variância de (b) & $1,907 \mathrm{E}-6$ & $3,122 \mathrm{E}-6$ & $9,034 \mathrm{E}-7$ & $4,434 \mathrm{E}-6$ & $6,090 \mathrm{E}-7$ \\
\hline Variância de $\left(\mathrm{T}_{0}\right)^{(2)}$ & 46,6 & 124,5 & 27,0 & 147,3 & 13,4 \\
\hline Desvio-padrão $\left(\mathrm{T}_{0}\right)(\mathrm{min})$ & 6,8 & 11,1 & 5,2 & 12,1 & 3,7 \\
\hline Período de centrifugação $\left(\mathrm{T}_{0}\right)$ (min) & 83,1 & 90,8 & 113,5 & 90,0 & 130,1 \\
\hline Limite inferior de $\left(\mathrm{T}_{0}\right)(\mathrm{min})^{(3)}$ & 69,3 & 68,2 & 103,0 & 65,5 & 122,7 \\
\hline Limite superior de $\left(\mathrm{T}_{0}\right)(\min )^{(3)}$ & 96,9 & 113,2 & 124,0 & 114,5 & 137,5 \\
\hline
\end{tabular}

(1) Inverso de $\mathrm{F}(0,05 ; 2 ; 6)=5,14325$

${ }^{(2)}$ Expressão da equação 9: $\operatorname{var}\left(\mathrm{T}_{0}\right)=\frac{\operatorname{var}(\mathrm{a})}{\mathrm{b}^{2}}-\frac{2\left(\mathrm{a}-\ln \mathrm{F}_{0}\right) \operatorname{cov}(\mathrm{a}, \mathrm{b})}{\mathrm{b}^{3}}+\frac{\left(\mathrm{a}-\ln \mathrm{F}_{0}\right)^{2} \operatorname{var}(\mathrm{b})}{\mathrm{b}^{4}}$.

(3)Expressão da equação 10: $\mathrm{T}_{\mathrm{c}}=\mathrm{T}_{0} \pm 2,015 \sqrt{\operatorname{var}\left(\mathrm{T}_{0}\right)^{\mathrm{b}^{3}}}$. 
e o RQ, resultando num desvio-padrão de 11,1 e $12,1 \mathrm{~min}$, respectivamente. Os tempos de centrifugação necessários ao equilíbrio da umidade no solo foram de $83,1 \pm 6,8 ; 90,8 \pm 11,1 ; 113,5 \pm 5,2$; 90,0 $\pm 12,1$ e 130,1 $\pm 3,7$ min, no LVA muito argiloso, LVA argilo-arenoso, LVA franco-arenoso, RQ e LV argiloso, respectivamente.

\section{Conclusões}

1. O período de centrifugação da amostra de solo influencia a curva de retenção da umidade, afetando principalmente os valores da umidade nas tensões mais elevadas, alterando, portanto, a umidade residual.

2. O período de centrifugação necessário para o equilíbrio da tensão da umidade do solo, na determinação da curva de retenção, pelo método tradicional da centrífuga, deve ser superior a 80 minutos.

\section{Agradecimentos}

Aos assistentes de pesquisa Wantuir Caixeta Vieira e Joviano Mateus Pires da Embrapa-Centro de Pesquisa Agropecuária dos Cerrados; aos professores Lúcio Vivaldi e Geraldo de Silva e Souza pelas valiosas orientações nas análises estatísticas empregadas.

\section{Referências}

ABRAMOWITZ, M.; STEGUN, I. A. Handbook of mathematical functions with formulas, graphs, and mathematical tables. Washington: U S Government Printing Office, 1972. p. 987, 990.

ADÁMOLI, J.; MACEDO, J.; AZEVEDO, L. G. de; MADEIRA NETTO, J. Caracterização da região dos Cerrados. In: GOEDERT, J. W. (Ed.). Solos dos cerrados. Brasília: Embrapa-CPAC/Nobel, 1985. p. 33-74.

ASSOULINE, S.; TESSIER, D.; BRUAND, A. A conceptual model of the soil water retention curve. Water Resources Research, Washington, v. 34, n. 2, p. 223231, 1998.

BRIGGS, L. J.; McLANE, J. W. Moisture equivalent determinations and their application. Proceedings of the American Society of Agronomy, v. 2, p. 138-147, 1910.

DRAPER, N. R.; SMITH, H. Applied regression analysis. New York: J. Wiley, 1981. 709 p.

FREITAS JÚNIOR, E.; SILVA, E. M. da. Uso da centrífuga para determinação da curva de retenção de água do solo, em uma única operação. Pesquisa Agropecuária Brasileira, Brasília, v. 19, n. 11, p. 1423-1428, nov. 1984.

GENUTCHEN, M. T. van. A closed form equation for predicting the hydraulic properties of unsaturated soils. Soil Science Society of America Journal, Madison, v. 44, p. 892-898, 1980.

GENUTCHEN, M. T. van; NIELSEN, D. R. On describing and predicting the hydraulic properties of unsaturated soils. Annales Geophysicae, Berlin, v. 3, n. 5, p. 615628, 1985.

KOKUSAN CORPORATION (Tokyo, Japão). Moisture equivalent centrifuge: model H-1400pF. Tokyo, 1999. $21 \mathrm{p}$.

KOOL, J. B.; PARKER, J. C.; GENUTCHEN, M. T. van. Parameter estimation for unsaturated flow and transport models: a review. Journal of Hydrology, Amsterdam, v. 91, p. 255-293, 1987.

MALCOM, J. R.; ANDRÉE, D. C. Water release characteristics. In: SMITH, K. A.; MULLINS, C. E. (Ed.). Soil analysis: physical methods. New York: M. Dekker, 1991. p. 111-160.

MEDEIROS, S. M. Determinação da curva de retenção de água através de amostras submetidas à centrifugação. 1987. 66 f. Dissertação (Mestrado) - Escola Superior de Agricultura Luiz de Queiroz, Piracicaba, 1987.

MICROSOFT CORPORATION (Redmond, Estados Unidos). Microsoft Excel, versão 5.0: guia do usuário. Redmond, 1994. p. 589-603.

ODÉN, S. An integral method for determination of moisture retention curves by centrifugation. Grundförbättring, Uppsala, v. 27, p. 137-143, 1976.

RICHARDS, L. A.; FIREMAN, M. Pressure plate apparatus for measuring moisture sorption and transmission by soils. Soil Science, Baltimore, v. 56, p. 395-404, 1943.

ROGOWSKI, A. S. Watershed physics: model of soil characteristics. Water Resources Research, Washington, v. 7, p. 1575-1582, 1971.

SILVA, E. M. da. Analysis of furrow irrigation uniformity as affected by furrow spacing. 1990. 449 leaves. Thesis (Ph.D.) - University of Arizona, Tucson, 1990.

SOUZA, G. da S. e. Introdução aos modelos de regressão linear e não-linear. Brasília: Embrapa-SPI/EmbrapaSEA, 1998. $505 \mathrm{p}$. 